\title{
THE IMPACT OF CAPITAL STRUCTURE ON ECONOMIC CAPITAL AND RISK ADJUSTED PERFORMANCE
}

\author{
BY
}

Bruce T. Porteous and Pradip Tapadar

\begin{abstract}
The impact that capital structure and capital asset allocation have on financial services firm economic capital and risk adjusted performance is considered. A stochastic modelling approach is used in conjunction with banking and insurance examples. It is demonstrated that gearing up Tier 1 capital with Tier 2 capital can be in the interests of bank Tier 1 capital providers, but may not always be so for insurance Tier 1 capital providers. It is also shown that, by allocating a bank or insurance firm's Tier 1 and Tier 2 capital to higher yielding, more risky assets, risk adjusted performance can be enhanced. These results are particularly pertinent with the advent of the new Basel 2 and Solvency 2 risk based capital initiatives, for banks and insurers respectively.
\end{abstract}

\section{KEYWORDS}

Asset allocation, capital gearing, economic capital, financial services firms risk adjusted performance, stochastic models, Tier 1 and Tier 2 capital.

\section{INTRODUCTION}

With the advent of new risk based regulations for financial services firms, specifically Basel 2 for banks and Solvency 2 for insurers, quantitative risk management has taken a step change in importance for firms, capital providers and regulators. For example, financial services firms are now expected, and required, to self assess and quantify the amount of capital that they need to cover the risks they are running. This self assessed quantum of capital is commonly termed risk, or economic, capital.

In this article we will use the term economic capital throughout. We also use the term actual capital to mean the total amount of equity and debt capital that the firm has raised to back its business, particularly its economic capital amount. Porteous and Tapadar (2005), in their recent book, have given a very comprehensive discussion of economic capital for financial services conglomerates, and we will build on this work, and their examples, wherever possible. 
See also the articles by Porteous, McCulloch and Tapadar (2003), Porteous (2004) and Porteous (2005) which provide further detailed examples and discussion of economic capital for financial services firms using the ideas presented in Porteous and Tapadar (2005). The books by Dev (2004) and Matten (2000) also contain relevant material.

\subsection{Two Fundamental Questions}

Hereafter, we will assume that firms use economic capital as a key risk management tool in the running of their businesses. The article is then concerned with two fundamentally important questions regarding how firms structure their actual capital, and how they invest it.

The first fundamental question that we consider is as follows:

QUESTION 1: How does a firm's economic capital amount depend on the equity-debt capital structure of the actual capital that is backing it and what impact does this structure have on the risk adjusted returns earned on the firm's equity capital?

When raising fresh capital, or when reorganising their capital structures, firms will want to understand what impact capital structure has on capital efficiency. For example, backing economic capital with increased amounts of debt capital, rather than equity, increases the leverage of the equity capital. But, do the returns earned on the more highly leveraged equity capital compensate the equity capital providers for the additional risks that they are taking on? This difficult question is further complicated by the fact that a firm's economic capital amount itself depends on the equity-debt capital structure of the actual capital backing it.

The second fundamental question that we consider is:

QUESTION 2: How does a firm's economic capital amount depend on the asset allocation of the actual capital that is backing it and what impact does this asset allocation have on the risk adjusted returns earned on the firm's equity capital?

Firms often invest their actual capital in low risk assets, such as short term cash. However, if a firm chooses to invest its actual capital in more risky, but higher earning, assets such as equity assets, is this in the best interests of the firm's equity capital providers? Investing in equity assets is clearly more risky for the equity capital providers, but are they adequately compensated by the higher returns that they might expect to earn? This question is again further complicated by the fact that economic capital, itself, depends on the asset allocation of the actual capital that is backing it.

In the Sections that follow, we study and investigate these two fundamental questions via the construction of illustrative examples. 


\subsection{Why is Economic Capital Important?}

Firms, regulators, ratings agencies and capital providers all have a very keen interest in economic capital, for the following main reasons.

Firms: Comparison of the firm's actual capital to its economic capital allows the firm to assess if it has enough actual capital to cover the risks that it is running. If it does not, then it should consider raising more actual capital, or de-risking its balance sheet. If it holds more actual capital than economic capital, then this may be inefficient, deflating equity capital provider returns, and the firm may therefore wish to consider reorganising its balance sheet.

Regulators: A firm's regulatory capital amount should, at least in theory, represent a good approximation to its economic capital amount. Otherwise regulators may require firms to hold more actual capital than they need, which is inefficient, or less, which is imprudent, to cover the risks that the firm is running. If regulatory capital does not represent a good approximation to economic capital, regulators may wish to revisit firms' regulatory capital requirements and also to consider improving their regulations.

Rating agencies: In assessing the ability of a firm to service its actual capital, and the security of that capital, ratings agencies will be interested in comparing the firm's actual capital amount to its economic capital amount. For example, if the firm's actual capital is lower than its economic capital, under an optimistic self assessment of economic capital made by the firm, then the firm is potentially running too much risk for its capital base. This jeopardises the security of that actual capital, and also the firm's ability to service it. The rating agencies will therefore count this against the firm and will consequently allocate it a lower credit rating than they would otherwise do, if actual capital at least matched economic capital.

Capital providers: The providers of actual capital, both equity and debt capital, will want to know how secure their investment is and may require an assessment of the risks they are taking on, as well as an estimate of the risk adjusted returns that they are likely to earn. As described in Porteous and Tapadar (2005), economic capital can help the capital providers obtain answers to these questions, particularly by measuring risk adjusted firm performance using the rate of return earned on the equity capital that backs the firm's economic capital amount.

\subsection{Other Research}

Firm capital structure, and the rates of return earned by different types of capital providers, have been active areas of research for many years now. For example, as is now very well known, Modigliani and Miller (1958) showed that, under certain fairly restrictive assumptions, firm value is independent of capital structure.

This seminal work has been followed up by extensive research exploring, for example, the effect of relaxing various of the Modigliani-Miller assumptions. 
More recently, Rajan and Zingales (1995) have studied firm leverage across a number of different economies.

However, although there are many published articles and books that discuss the relationship between capital structure and the risk-reward relationship for equity and debt capital providers, this work does not generally approach the problem from the perspective of economic capital. It is this economic capital perspective, especially in the new Basel 2-Solvency 2 world, that makes the work presented here, we feel, of particular relevance.

The two fundamental questions considered here, which are expressed in economic capital terms, are of great practical importance in the new Basel 2Solvency 2 world as firms seek to optimise their capital structuring, asset allocation and management processes. We hope, therefore that, not only will the results presented here be of some practical use to firms, but the article will also encourage more work to be carried out in this important area.

\subsection{Structure of the Article}

The remainder of the article is structured as follows: in Section 2, we discuss the different types of capital that are eligible to count towards a firm's regulatory capital requirement. Section 3 defines and discusses economic capital and Section 4 describes the detailed assumptions that underpin our illustrative examples. The first example of a retail mortgage bank is relevant to Basel 2, whereas the second example of a life insurance annuity firm is relevant to Solvency 2 . Section 5 examines how economic capital and risk adjusted performance depend on the firm's equity-debt capital structure and Section 6 looks at how economic capital and risk adjusted performance depend on the asset allocation of the actual capital that backs it. Section 7 then considers how economic capital and risk adjusted performance depend jointly on a firm's equity-debt capital structure and its actual capital asset allocation. Finally, in Section 8, we draw together the main conclusions of the article and discuss optimal capital structuring, asset allocation and management processes for financial services firms.

\section{The Role of Capital and Different Types of Capital}

Actual capital, in its broadest sense, acts as a buffer to absorb losses incurred by financial services firms in times of financial stress. It therefore provides security and protection to customers owed money by the firm. For example, the depositors of a bank, or the individual pensions savers of a life insurance firm.

Three key properties of capital are therefore:

- It should be able to absorb losses.

- It should be available permanently.

- It should be fully paid up. 
Regulators grade capital by its quality, as discussed below, with the highest quality capital graded as Tier 1 and lower graded capital as Tier 2. Within Tier 1 there is also a sub-grading into Core Tier 1 and the lower graded Innovative Tier 1. Within Tier 2, there are sub-gradings, into Upper and Lower Tier 2, for example.

The rules that define whether a specific type of capital issued by a firm qualifies as Tier 1, or Tier 2, and how much of that capital instrument is eligible to be counted towards a firm's regulatory capital requirement, are somewhat arbitrary. For example, Tier 2 capital is usually eligible only up to the level of the firm's Tier 1 capital, with any excess amount beyond this level ineligible. Rather than describing the precise detail of these rules in this article, which we feel will not add much value, we prefer instead to focus on describing the key characteristics of Tier 1 type and Tier 2 type actual capital.

Tier 1 type actual capital tends to comprise mainly of what we term equity capital. In other words, share capital that is completely subordinated and perpetual with the ability to waive dividends, if required. We regard the providers of a firm's equity capital as the principal risk takers in supporting the business of the firm.

Tier 2 type actual capital tends to comprise mainly of what we term debt capital. In other words, loans which rank ahead of equity capital, and which are usually not permanent and do not have the ability to waive interest, although interest may be deferred.

With debt capital, if the firm is unable to pay, or defer, a scheduled interest or redemption payment, then a default event occurs. Depending on the debt capital issuance terms and conditions, the debt capital providers may have the right to call in their loans and to require the firm to restructure its actual capital in order to receive what is owed to them. Ultimately, the firm may have to be liquidated, although this would be a very extreme measure, to be used only if the firm is unable to continue trading.

Debt capital is attractive to firms as, unlike equity capital, its cost can be met out of before tax profits. This is one reason why debt capital is cheaper than equity capital, in addition to it also being less risky.

However, as described earlier, regulators regard debt capital less highly than equity capital. As a consequence, debt capital tends to be less eligible to count towards a firm's regulatory capital requirements than equity capital. The Holy Grail for firms, and their investment bank advisers, is hybrid capital that counts as debt capital for interest payment purposes, but as equity capital for regulatory capital eligibility purposes. This is an area of constant tension and friction between firms and their advisers, on the one hand, and regulators on the other.

In fact, the Basel Committee of the Bank for International Settlements and the European Commission have both initiated projects investigating capital definition and eligibility rules. This work can ultimately be expected to lead to new capital rules and regulations.

We now move on to define and discuss economic capital. As described in Sub-section 1.1, fundamental question 1, a key objective of this article is to 
understand what impact a firm's Tier 1-Tier 2 capital structure has on economic capital and risk adjusted performance.

\section{ECONOMIC CAPITAL}

Although economic capital is a ubiquitous term and is widely discussed within the financial services industry, surprisingly, there is no commonly accepted standard definition of it. In order to move forward and answer the two fundamental questions posed in Sub-section 1.1, we need a definition of economic capital that we can work with. Porteous and Tapadar (2005) define economic capital as:

Definition 1: Economic capital, for the business of a firm, is the amount of capital, or excess assets, that this business requires to ensure that its realistic, or market value, balance sheet remains solvent, over a specified time horizon, with a prescribed probability or confidence level, following events that are unexpected, yet not so unlikely that they might never occur in practice.

Basically, Definition 1 states that economic capital is the amount of capital that the business of a firm needs to keep its realistic balance sheet solvent under stress events. It is worth noting that, by design, this definition is completely independent of the firm's actual capital, particularly its structure and asset allocation.

In proposing this definition, Porteous and Tapadar (2005) made the following two implicit assumptions:

Implicit assumption 1: Once economic capital is quantified, it is backed entirely by equity capital. As the dividends paid on equity capital can be waived at the discretion of the firm, there is therefore no need to hold any additional capital, or excess assets, to provide for dividend payments under stress events. However, once debt capital is introduced, this is no longer the case. This is because the interest payments on debt capital generally cannot be waived. Additional capital, or excess assets, must then be held to provide for these interest payments in times of stress, to protect the providers of the debt capital.

Implicit assumption 2: The actual capital backing a firm's economic capital amount is invested in risk free short term cash assets and the economic capital requirements of the risks associated with these assets are negligible. If the firm's actual capital is invested in more risky assets, relative to short term cash, then the situation changes. For example, if the firm's actual capital is invested in equity assets, there is a possibility that, under a stress event, the actual capital may lose value and may no longer be sufficient to ensure that the realistic balance sheet of the firm's business remains solvent. Additional capital, or excess assets, may then be required to provide for these potential actual capital asset losses in times of stress. In other words, 
the firm's actual capital itself may have an economic capital requirement associated with the asset risks in which it is invested.

For the purposes of this article, we therefore propose the following enhanced definition of economic capital:

Definition 2: Economic capital for a firm is the total amount of capital, or excess assets, required to ensure:

- the realistic balance sheet of the firm's business remains solvent;

- the firm is able to meet its capital contractual obligations;

- the risks associated with the assets in which the firm's actual capital is invested are covered;

all following unexpected events that occur over a specified time horizon, with a prescribed probability.

It is fairly straightforward to see that when a firm introduces debt capital to back its economic capital, economic capital increases because additional assets are required to provide for the interest payments on the debt capital in times of stress. It is again straightforward to see that, as the debt capital increases, the gearing of the equity capital increases. The gearing effect causes the equity capital expected returns, and the volatility of those returns, to increase. However, the associated increase in economic capital, which we assume in this article is always provided for by equity capital, also deflates the equity capital returns. In short, it is less than straightforward to see how the equity capital provider's risk adjusted returns are altered by the introduction of debt capital.

Similarly, it is straightforward to see that, as firms allocate their actual capital to riskier, and so higher earning assets, the returns expected to be earned on the firm's equity capital will increase, as will the volatility of those earned returns. However, the consequent potential increase in economic capital resulting from allocating the firm's actual capital to more risky assets can cause these enhanced returns to be deflated. Again, it is not clear if the providers of the firm's equity capital are better off by allocating the firm's actual capital to riskier assets.

In Sections 5, 6 and 7, we will consider specific examples which provide some insight into these issues and questions. However, before doing this, we set out in Section 4 the detailed assumptions that underpin our illustrative examples.

\section{The Examples And Key Assumptions}

The basic structures of the examples that we use in this article are taken from Porteous and Tapadar (2005). We have built upon and enhanced these structures further for the purposes of this article. Specifically, the examples comprise a retail mortgage bank and a life insurance annuity firm. The former 
example is relevant to Basel 2, whereas the latter is relevant to Solvency 2. We provide a brief outline of the examples below, but please refer to Appendices 1 and 2 of this article and also Porteous and Tapadar (2005) for the full details.

\subsection{Stochastic Model}

The stochastic model that we use is a fairly standard 21 dimensional multivariate normal first order autoregressive time series model, where the multivariate dependency structure of the 21 individual response variables is modelled using a graphical model, as explained below.

The 21 individual univariate time series models, described below, model the within-series dependency, or serial dependency, structures of each of the individual response variables.

To model the between-series, or multivariate, dependency structure of the 21 individual response variables, we use a multivariate normal model where the correlation structure of the 21 dimensions is modelled using a graphical model, which describes the assumed conditional independence properties of the 21 dimensions. Graphical models are described briefly in Sub-section 4.1.1 below, but see Lauritzen (1996) and Porteous and Tapadar (2005) for fuller descriptions. They are extremely useful dimension reduction tools that can be used to explain very high dimensional dependency relationships amongst random variables using low dimensional clusters, or cliques, of relationships.

Note that the description of the stochastic model provided in this article completely specifies the model. This, therefore, allows the reader to reconstruct the model, or a similar model, if required.

In the examples that we consider in this article we will, in fact, use only a relatively small subset of the 21 response variables. In other words, we will use only those response variables that are needed to construct the examples, as is explained in Appendices 1 and 2.

\subsubsection{Investment Response Variables}

We model the $i$-th response variable at time $t, Z_{i t}$, as the sum of an unconditional expectation $\mu_{i}$ and a first order autoregressive time series with constant volatilities and correlations, although stochastic volatilites and correlations can also be accommodated if required. In other words, $Z_{i t}=\mu_{i}+Y_{i t}$, where:

$$
Y_{i t}=\beta_{i} Y_{i(t-1)}+\varepsilon_{i t} .
$$

The error terms $\varepsilon_{i t} \sim N\left(0, \sigma_{i}^{2}\right)$ and are assumed to be independently distributed across time. Note that $\mathrm{E}\left[Z_{i t}\right]=\mu_{i}$ and that the first order autoregressive parameter $\beta_{i}$ controls the strength of the within-series dependency for the $i$-th response variable. So, for example, "large" positive values of $\beta_{i}$ will mean 
TABLE 1

Stochastic Model: Univariate Model Parameterisation.

\begin{tabular}{|c|c|c|c|c|}
\hline & Investment Response Variable & $\begin{array}{c}\text { Unconditional } \\
\text { expectation } \\
\mu_{i}\end{array}$ & $\begin{array}{c}\text { First order } \\
\text { autoregressive } \\
\text { parameter } \\
\beta_{i}\end{array}$ & $\begin{array}{l}\text { Unconditional } \\
\text { standard deviation } \\
\text { of error terms } \\
\sigma_{i} / \sqrt{1-\beta_{i}^{2}}\end{array}$ \\
\hline & UK Economic & & & \\
\hline 1 & Retail Price Inflation (“RPI”) & 0.0275 & 0.975 & 0.00750 \\
\hline 2 & Equity earnings/dividend growth & 0.0425 & 0.950 & 0.02000 \\
\hline 3 & Equity dividend yield & 0.0325 & 0.975 & 0.00750 \\
\hline 4 & Short term cash yield & 0.0475 & 0.975 & 0.00750 \\
\hline 5 & Medium term government bond yield & 0.0500 & 0.975 & 0.01875 \\
\hline 6 & Medium term corporate bond yield & 0.0550 & 0.975 & 0.01875 \\
\hline 7 & Long term government bond yield & 0.0525 & 0.975 & 0.01875 \\
\hline 8 & Long term corporate bond yield & 0.0575 & 0.975 & 0.01875 \\
\hline 9 & Mortgage Yield & 0.0575 & 0.975 & 0.00750 \\
\hline 10 & Property rental growth & 0.0325 & 0.950 & 0.01875 \\
\hline 11 & Property rental yield & 0.0425 & 0.975 & 0.00750 \\
\hline 12 & $£$ appreciation against $\$$ & 0.0200 & 0.000 & 0.02500 \\
\hline & US economic & & & \\
\hline 13 & Consumer Price Inflation (“CPI”) & 0.0200 & 0.975 & 0.00750 \\
\hline 14 & Equity earnings/dividend growth & 0.0625 & 0.950 & 0.02000 \\
\hline 15 & Equity dividend yield & 0.0200 & 0.975 & 0.00750 \\
\hline 16 & Short term cash yield & 0.0200 & 0.975 & 0.00750 \\
\hline 17 & Medium term government bond yield & 0.0375 & 0.975 & 0.01875 \\
\hline 18 & Medium term corporate bond yield & 0.0425 & 0.975 & 0.01875 \\
\hline 19 & Long term government bond yield & 0.0450 & 0.975 & 0.01875 \\
\hline 20 & Long term corporate bond yield & 0.0500 & 0.975 & 0.01875 \\
\hline 21 & Mortgage Yield & 0.0425 & 0.975 & 0.00750 \\
\hline
\end{tabular}

that there will be very strong positive serial dependency within the $i$-th response variable.

Table 1 shows the parameterisation of the 21 univariate autoregressive time series models that make up the full 21 dimensional stochastic model. The annual expected values, the $\mu_{i} \mathrm{~s}$, and the annual standard deviations, the $\sigma_{i} / \sqrt{1-\beta_{i}^{2} s}$, of the individual response variables are also shown.

The correlation structure of the $\varepsilon_{i}$ error terms is modelled using a graphical model, as displayed in Figure 1. In this figure, response variable error terms that are directly connected to each other correlated, with the assumed constant correlation coefficient values $\rho_{i j}$, as set out in Table 2 . 


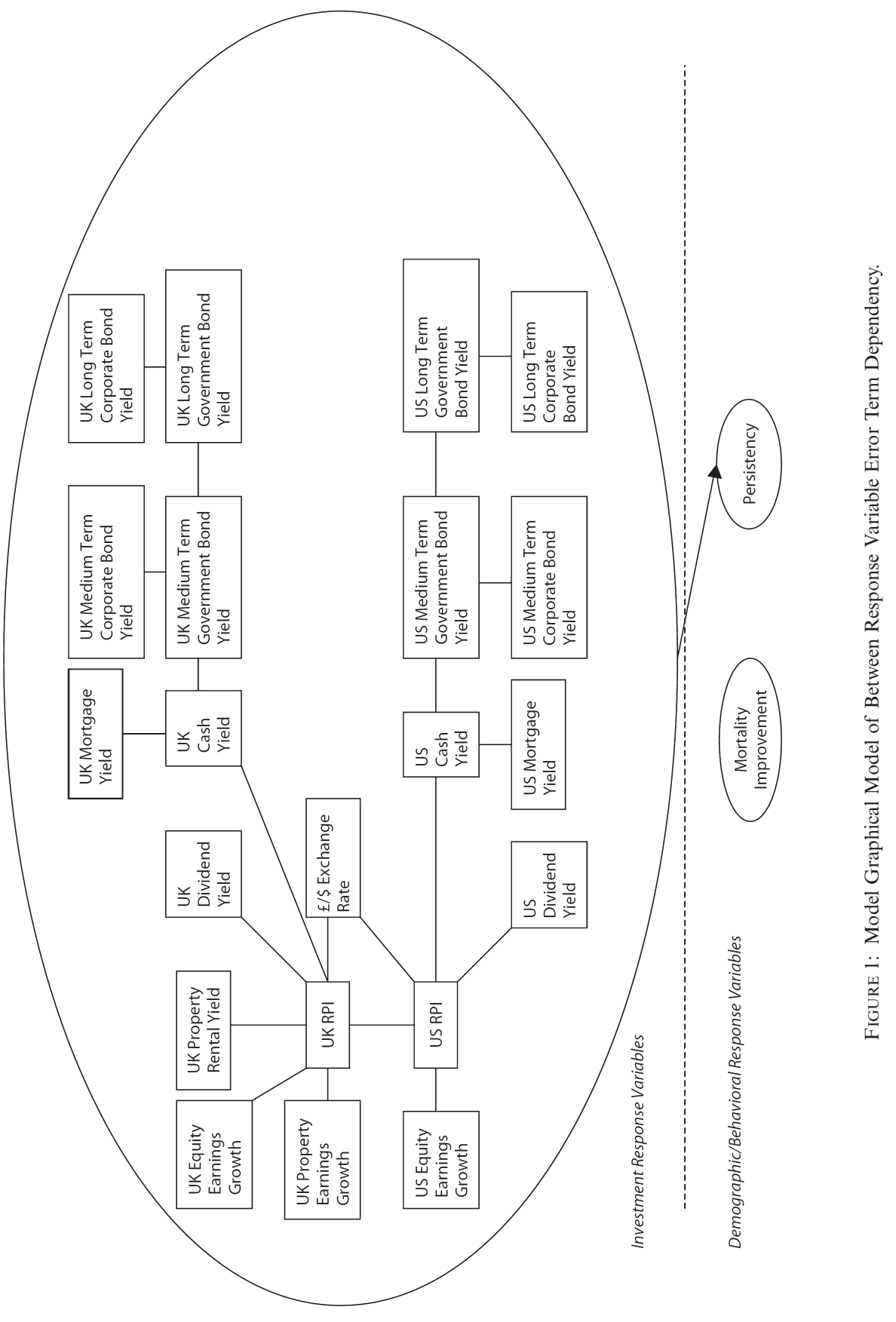


TABLE 2

Stochastic Model: Error Term Correlation Parameterisation.

\begin{tabular}{cc}
\hline \hline$\varepsilon$-pair & Correlation coefficient $\rho_{i j}$ \\
\hline 1,2 & 0.1 \\
1,3 & 0.3 \\
1,4 & 0.6 \\
1,10 & 0.1 \\
1,11 & 0.3 \\
1,12 & 0.6 \\
1,13 & 0.3 \\
4,5 & 0.6 \\
4,9 & 0.6 \\
5,6 & 0.6 \\
5,7 & 0.6 \\
7,8 & 0.6 \\
12,13 & 0.6 \\
13,14 & 0.1 \\
13,15 & 0.3 \\
13,16 & 0.6 \\
16,17 & 0.6 \\
16,21 & 0.6 \\
17,18 & 0.6 \\
17,19 & 0.6 \\
19,20 & 0.6 \\
\hline \hline
\end{tabular}

Response variable error terms that are indirectly connected in Figure 1, via other directly connected error terms, are still statistically dependent, and so are correlated, but more weakly so. This is a property of graphical models. Such error terms are, however, conditionally independent of each other, given the error terms that connect them, again a property of graphical models. See Porteous and Tapadar (2005) Appendix 7.1 for the full 21 X 21 error term correlation matrix which is completely specified by the graphical model parameterisation described here.

A full justification for the Table 1 and 2 parameterisations of the stochastic model, and the error term multivariate normality assumption, is provided in Porteous and Tapadar (2005) and the references contained therein. It is demonstrated there, and also in Porteous (2004) and Porteous (2005), that this stochastic model represents a very good first order approximation to the real investment markets that it is modelling.

Two demographic/behavioural response variables, mortality improvement and customer persistency, can also be seen in Figure 1. Whilst the rate at which mortality improves does not directly depend on investment markets, customer 
persistency behaviour can, in practice, depend on investment conditions, as described below.

\subsubsection{Mortality Improvement}

The UK actuarial profession, amongst other professional bodies, UK government departments and international agencies, studies mortality and regularly publishes mortality tables, including allowances for future mortality improvements. The data that are used for these actuarial studies are provided by the UK life insurance industry. See Willets et al (2004) and Willets (2004), two recent mortality studies prepared under the auspices of the UK actuarial profession, and which provide good overviews of current mortality trends, for more information.

Table 3, taken from Willets (2004), shows estimated annual mortality improvement rates by age and calendar year for males in the general population of England and Wales. The improvement rates are estimated over a five year period centred on the calendar year shown. See Willets (2004).

TABLE 3

Average Annual Mortality Improvement Rates for Males In the Population of England AND Wales.

\begin{tabular}{c|cccccc}
\hline \hline \multirow{2}{*}{ Age Group } & \multicolumn{7}{|c}{ Calendar Year } \\
\cline { 2 - 7 } & 1975 & 1980 & 1985 & 1990 & 1995 & 2000 \\
\hline $40-44$ & $\mathbf{3 . 1} \%$ & $2.1 \%$ & $1.6 \%$ & $0.1 \%$ & $0.3 \%$ & $0.9 \%$ \\
$45-49$ & $\mathbf{2 . 9} \%$ & $\mathbf{3 . 5} \%$ & $\mathbf{2 . 8} \%$ & $\mathbf{3 . 1} \%$ & $0.4 \%$ & $0.2 \%$ \\
$50-54$ & $1.0 \%$ & $\mathbf{3 . 7} \%$ & $\mathbf{2 . 6} \%$ & $\mathbf{2 . 3} \%$ & $2.9 \%$ & $1.7 \%$ \\
$55-59$ & $1.5 \%$ & $1.8 \%$ & $\mathbf{2 . 6} \%$ & $\mathbf{3 . 1} \%$ & $2.4 \%$ & $3.5 \%$ \\
$60-64$ & $1.0 \%$ & $2.1 \%$ & $2.0 \%$ & $\mathbf{3 . 6} \%$ & $\mathbf{3 . 6} \%$ & $3.2 \%$ \\
$65-69$ & $1.6 \%$ & $2.2 \%$ & $1.7 \%$ & $2.1 \%$ & $\mathbf{3 . 8} \%$ & $\mathbf{4 . 5} \%$ \\
$70-74$ & $1.6 \%$ & $1.9 \%$ & $1.8 \%$ & $2.0 \%$ & $2.5 \%$ & $\mathbf{4 . 6} \%$ \\
$75-79$ & $0.5 \%$ & $2.1 \%$ & $1.4 \%$ & $2.2 \%$ & $2.6 \%$ & $2.8 \%$ \\
\hline \hline
\end{tabular}

A cohort effect can be seen in the bold figures shown in Table 3 and note also that, over calendar years, improvement rates have fallen at the younger ages, but have increased at the older ages. Willets et al (2004) discuss the reasons for this in detail.

Our approach to modelling mortality improvement risk stochastically is as follows:

- We start with a base mortality table that represents a good estimate of current mortality for the population under consideration. 
- Expected improvement factors, along the lines set out in Table 3, are then assumed and represent our best estimate expected mortality improvement rate factors.

- These expected improvement factors will generally depend on the starting ages of the lives being modelled in the projection, their sex, any cohort effects and by duration within the projection.

- We perturb these expected improvement factors by the addition of a Normally distributed stochastic error term to represent the uncertainty that is prevalent in estimating future mortality improvement factors.

- The stochastically generated improvement factors are then used to project the base mortality table forward in time.

\subsubsection{Customer Persistency}

In the mortgage bank example that we describe next, we assume that customers become less persistent as the mortgage standard variable rate rises and mortgages become more expensive. This is because it then becomes more financially beneficial for customers to remortgage away from their current provider onto a cheaper mortgage product, typically a new discounted rate mortgage or fixed rate mortgage, provided by another bank.

On the other hand, with profits life insurance customers tend to become more persistent as equity asset markets fall, because the investment guarantees provided by such products are then perceived to have more value.

These two product examples illustrate how customer persistency depends, not only investment markets, but also on the specific financial services product being considered.

\subsection{Basel 2 Retail Mortgage Bank Example}

We consider a 20 year capital repayment floating rate mortgage and use the stochastic model described in Section 4.1 to model the mortgage product response variables, and associated derived variables, as described in Appendix 1.

We assume that the bank funds its mortgages using the wholesale funding markets and that the cost of this funding equals the short term UK cash yield, as generated by the stochastic model, plus $10 \mathrm{bp}$.

From Table 1 it can be seen, therefore, that the bank's expected interest rate margin equals $0.0575-0.0475-0.0010=0.0090$. This is reasonably representative of the UK banking industry, given the very intense competition that is currently seen in the UK mortgage market.

The corresponding interest rate margin annual standard deviation, under the Table 1 and Table 2 parameterisations, and which is driven mainly by the assumed correlation between the short term UK cash yield and the UK mortgage yield, is 0.0067 . This would not be unusual for a wholesale funded firm but may be on the high side for a retail funded firm. 
Similarly, as is described in Appendix 1, the bank's customers are assumed to be less persistent than expected when the mortgage standard variable rate that the bank charges its customers, as generated by the stochastic model, is "high". So, "high" mortgage payments are assumed to be a driver of low persistency, with this behaviour modelled stochastically via the standard variable rate response variable generated by the stochastic model.

Based on the stochastic elements of this example, described in Appendix 1, the economic capital requirement that is generated by the stochastic model is the amount of capital required by the bank to cover its aggregate:

1. Interest rate margin risks.

2. Expense risks.

3. Credit risks.

4. Persistency risks.

all beyond the expected amounts loaded into the mortgage product pricing to cover these risks.

We now describe how stochastic economic capital and the corresponding Pillar 1 minimum regulatory capital requirement are calculated.

\subsubsection{Bank Economic Capital Calculation}

The process that we use to calculate the bank's economic capital and its Pillar 1 minimum regulatory capital requirement, at any time point, is as follows:

Step 1. The stochastic model is used to generate one "future" scenario. In otherwords, the stochastic model is run forwards in time to generate monthly future values for all 21 response variables in the stochastic model. The bank example depends on a subset of these 21 response variables and it can therefore be determined, over its lifetime, using this future scenario. For example, the bank's cost of funding, for each month over the entire lifetime of the bank, can be calculated using the UK cash yields generated by the stochastic model.

Step 2. Based on this simulated future, at every month $t$ over the projected lifetime of the bank, the future profits that the bank will earn from its mortgage book can be calculated. This can be achieved because, once the simulated future has been generated, all future variables on which the bank's profits depend are known and the bank's profits for every future month over its lifetime can then be calculated. We can then also calculate $P V I F_{t}$ the present value, at time $t$, of all future profits that are expected to emerge from the bank's in force book of business. As $P V I F_{t}$ is equivalently an estimate of the economic value of the bank's in force mortgage book at time $t$, it also equals the estimated market value of the bank's mortgage book assets less the estimated market value of the bank's mortgage book liabilities at time $t$. 
Step 3. In calculating $P V I F_{t}$, we discount the future profits that emerge from the bank's mortgage book using the returns earned by the bank's actual capital assets, as generated by the stochastic model under this simulated future. In other words, we assume that profits are transferred to actual capital, as they emerge, and are then invested in the same assets as the bank's actual capital is invested.

Step 4. If $P V I F_{t}$ is negative, the estimated market value of the bank's mortgage book assets is less than the estimated market value of its mortgage book liabilities. In other words, the estimated market value balance sheet of the bank's mortgage book is insolvent and capital of amount $-P V I F_{t}$ must be injected to restore solvency.

Step 5. For each month $t$, we calculate the maximum value of all future $-P V I F_{s}$, for all $s>=t$, after having discounted back from $s$ to $t$. In doing this, we discount using the returns earned by the bank's actual capital assets as described in Step 3. This amount, which we denote $C_{t}$ and which is subject to a minimum value of zero, represents the amount of capital that must be injected at time $t$ to ensure that the bank's mortgage book estimated market value balance sheet always remains solvent throughout its remaining lifetime.

Step 6. The stochastic model is re-run to generate other future scenarios and the above computations are repeated.

Step 7. Once the above exercise has been repeated a large number of times, 50,000 runs of the stochastic model in this example, the $C_{t} s$ are put in increasing order over the 50,000 simulations of the stochastic model at each duration $t$. The high percentiles of the $C_{t} s$ then determine the economic capital requirements of the bank's mortgage book at each duration $t$. For example, the 99.5th percentile represents an estimate of the amount of capital that must be injected at time $t$ to ensure that, with probability 0.995 , under this stochastic model, the bank's mortgage book estimated market value balance sheet stays solvent over its remaining lifetime.

Step 8. The Basel 2 Pillar 1 minimum regulatory capital requirements are also calculated, at each duration, for all of the 50,000 stochastic simulations. Average capital requirements, across simulations and for each duration, are then calculated. It is these average minimum regulatory capital requirements that we compare to our stochastically generated economic capital amounts.

We use average Pillar 1 minimum regulatory capital requirements in our comparisons with economic capital for the following reasons:

1. Pillar 1 minimum regulatory capital requirements are calibrated by regulators to achieve low prescribed probabilities of firm insolvency under "through the cycle", or average, economic conditions. 
2. It is the Pillar 2 regulatory capital requirement that is designed by regulators to capture the capital requirements of less normal, or extreme, economic conditions.

Our retail mortgage bank example results are described in Sections 5, 6 and 7 below.

\subsection{Solvency 2 Life Insurance Annuity Firm Example}

In this example, we have chosen to model a joint life last survivor annuity for a male aged 65 and a female aged 65 . The annuity income is assumed to be level and is paid until both lives have died. We assume that the life insurance annuity premium is invested in long term UK corporate bonds.

We again model the product response variables stochastically using the model described in Section 4.1. The very detailed assumptions that underpin this example are set out in Appendix 2.

However, to help explain how the stochastic model links to the example, we briefly describe how credit risk is modelled. Credit risk losses are assumed to be at "expected" levels, unless corporate bond yields, as generated by the stochastic model, reach certain extreme "high" values. In this event, it is assumed that credit risk losses increase sharply to higher levels, as default probabilities and losses given default increase. In other words, high corporate bond yields are taken as an indicator of a less favourable economic climate which leads to higher levels of credit risk losses. In this sense, therefore, credit risk is modelled stochastically through the corporate bond yields generated by the stochastic model.

\subsubsection{Stochastically Modelled Response Variables}

Based on the stochastic elements of this example, as described in Appendix 2, the economic capital requirement that is generated by the stochastic model is the amount of capital required to cover aggregate:

- Market risks as a result of corporate bonds generating inadequate returns.

- Credit risks as a result of corporate bonds generating excessive credit losses.

- Expense risks as a consequence of RPI related unit costs increasing in line with high levels of RPI.

- Longevity risks as a consequence of rapidly improving mortality experience.

all beyond the expected amounts loaded into the annuity product pricing to cover these risks.

\subsubsection{Life Insurance Annuity Firm Economic Capital Calculation}

The method described in Section 4.2.1, used for our retail mortgage bank example, is again used. Note that for the life insurance annuity firm example 
we have used 10,000 simulations, rather than the 50,000 used for our banking example. This is because, as the annuity projections are more complex, and are for longer terms, they take longer to calculate and our computing resources precluded the running of 50,000 simulations.

Our life insurance annuity results are described in Sections 5, 6 and 7 below.

\subsection{Capital Assumptions}

A key assumption that we make in our examples is that each firm's Tier 1 capital comprises 100 per cent of equity capital and that each firm's Tier 2 capital comprises 100 per cent of debt capital. The cost of the Tier 2 capital is assumed to equal the UK short term cash yield, plus a margin of 0.5 per cent. We have checked that this specific margin assumption affects our results entirely as expected, with economic capital increasing with the size of the margin, and with all of our conclusions reported here still applying.

We further assume that the firm's total Tier 1 capital plus Tier 2 capital equals the firm's economic capital requirement at all durations. Movements in the firm's economic capital amount, by duration, are then matched by either injections, or releases, of Tier 1 and Tier 2 capital to exactly track economic capital movements.

In doing this, we assume that the firm is always able to raise sufficient Tier 1 and Tier 2 capital to back economic capital at all times. So, if the firm's economic capital increases because it is taking more risk, we assume that Tier 1 and Tier 2 capital is available to cover this increase at the same cost as described above. Obviously, in practice, this may not always be the case, especially if the firm is not performing well.

\section{The Impact of Tier 1-Tier 2 Capital Structure ON ECONOMIC CAPITAL}

We now illustrate the impact that the Tier 1-Tier 2 capital structure of a firm has on its economic capital amount and the corresponding returns earned by the Tier 1 capital providers for different Tier 1-Tier 2 capital structures.

We call the firm's economic capital amount, when it is backed 100 per cent by Tier 1 capital, the base economic capital amount. We then consider the impact of backing this base economic capital amount with 25 per cent, 50 per cent, 75 per cent and 100 per cent Tier 2 capital. It is assumed that any consequential increase in economic capital, from the base economic capital amount, arising from the Tier 2 capital backing, is backed 100 per cent by Tier 1 capital.

Economic capital increases when Tier 2 capital is introduced, firstly, because firm profits are reduced by Tier 2 capital costs, which are charged for explicitly. Secondly, the Tier 2 capital costs, which are themselves generated stochastically, introduce further volatility into firm profits. These reduced, and more volatile, profits are then spread across lower amounts of Tier 1 capital, provided that 
the associated economic capital increase, beyond the base economic capital amount, is not too large. Given all of these moving parts, it is far from obvious, therefore, to see what impact the gearing up of Tier 1 capital has on the risk adjusted returns earned by the Tier 1 capital providers.

Unless stated otherwise, we assume that the actual capital backing economic capital, and Pillar 1 minimum regulatory capital, is allocated to cash.

Our results are presented in the form of a series of figures and tables, as described below.

\subsection{Bank Capital Structure Example}

The first graph shown in Figure 2 displays 99.5th percentile economic capital for the range of Tier 2 capital backings considered. Pillar 1 minimum regulatory capital is also shown for comparison.

As expected, it can be seen that 99.5th percentile economic capital increases as the amount of Tier 2 capital backing of economic capital increases, although the increases are relatively modest. It can also be seen, as noted previously by Porteous and Tapadar (2005), that Pillar 1 capital is not a good approximation to economic capital.

The second graph in Figure 2 shows corresponding probability density function estimates for earned rates of return on Tier 1 capital ("ROEC"), and also on Pillar 1 capital, as generated by the simulations used to develop this example. The probability density function estimates were obtained using standard statistical kernel density estimation techniques.

In Table 4 we show various ROEC summary statistics, again based on the simulations used to construct the example, and including what we call the "Sharpe ratio", defined as mean return divided by standard deviation return. This ratio is a potential measure of risk adjusted performance and, in statistical terminology, is equivalent to the inverse of a coefficient of variation, or a random variable standardised to have a standard deviation of one.

Inspection of the probability density functions shown in Figure 2 shows that "gearing up" Tier 1 capital, by backing increasing proportions of economic capital with Tier 2 capital, moves the densities to the right and also increases their skewness. In other words, ROECs generally increase, with the upside potential of "high" ROECs also increasing, but with very little, or no, downside risk of "low" ROECs. This behaviour can also be seen in the summary statistics shown in Table 4. We have strong evidence, therefore, to conclude that, for this example, gearing up Tier 1 capital is advantageous for the Tier 1 capital providers.

It is also interesting to note from Table 4 that the opposite conclusion is reached if the Sharpe ratio is used to assess performance. In other words, a Tier 1 capital provider who measures risk using volatility, or standard deviation, may conclude that gearing up Tier 1 capital reduces risk adjusted performance. This conclusion is clearly invalid and consideration of the full shape of the probability density functions shown in Figure 2 is necessary before the Tier 1 

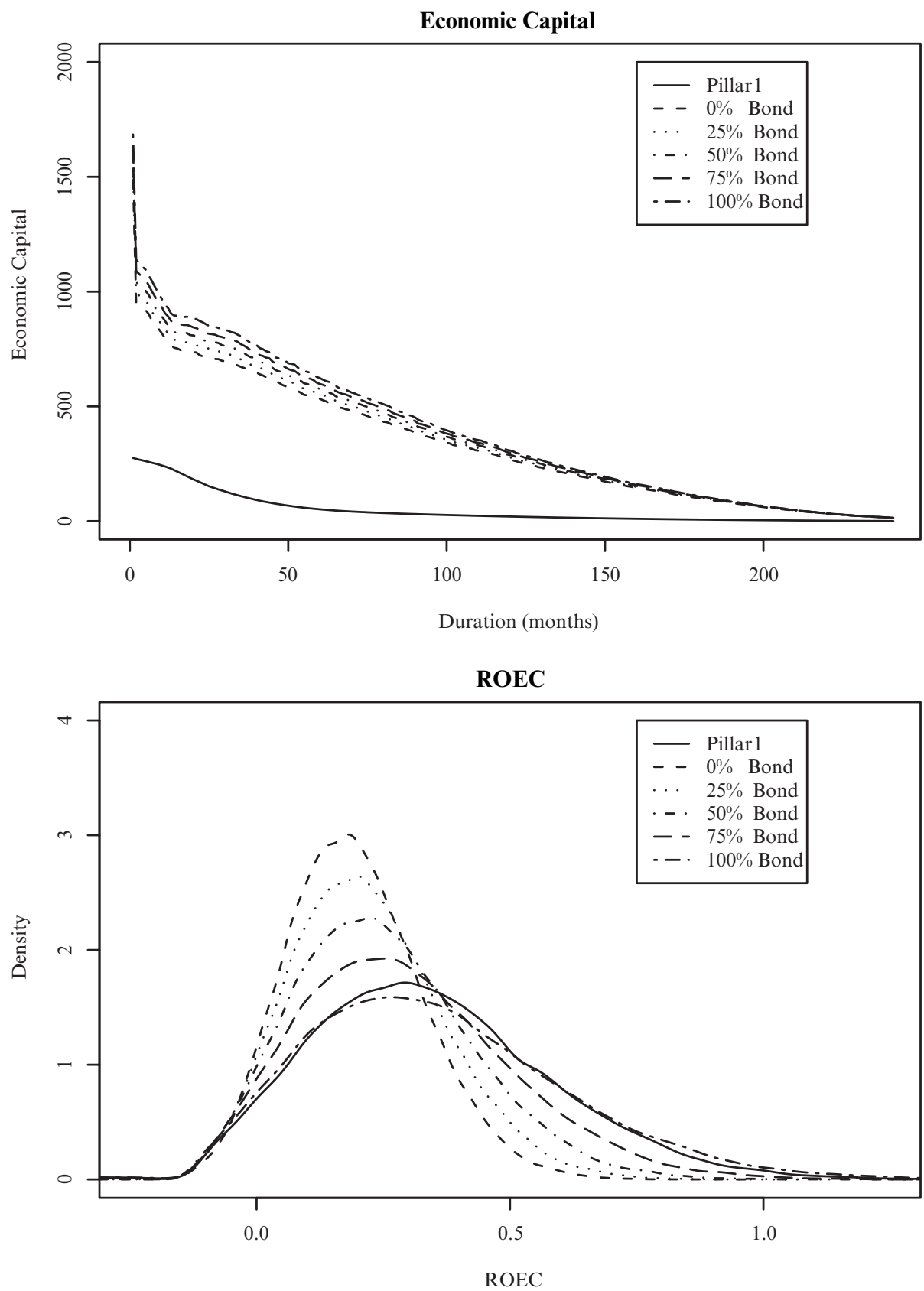

Figure 2: Bank: 99.5th Percentile Economic Capital and ROEC Probability Density Functions for Different Tier1-Tier2 Capital Structures. 
TABLE 4

Summary Statistics for 99.5Th Percentile ROEC for a Bank with Different Tier1-Tier2 Capital Structures ( $\mu=$ Mean, $\sigma=$ Standard Deviation, $Q_{1}=$ First Quartile, $Q_{2}=$ Second Quartile (Median), $Q_{3}=$ Third Quartile).

\begin{tabular}{c|cccccc}
\hline \hline & $\mu$ & $\sigma$ & Sharpe Ratio & $Q_{1}$ & $Q_{2}$ & $Q_{3}$ \\
\hline Pillar 1 & 0.344 & 0.239 & 1.439 & 0.172 & 0.323 & 0.490 \\
$0 \%$ Tier 2 & 0.195 & 0.134 & 1.454 & 0.099 & 0.186 & 0.280 \\
$25 \%$ Tier 2 & 0.217 & 0.153 & 1.416 & 0.108 & 0.206 & 0.314 \\
$50 \%$ Tier 2 & 0.247 & 0.179 & 1.384 & 0.120 & 0.233 & 0.359 \\
$75 \%$ Tier 2 & 0.290 & 0.212 & 1.370 & 0.138 & 0.271 & 0.420 \\
$100 \%$ Tier 2 & 0.353 & 0.259 & 1.366 & 0.165 & 0.325 & 0.509 \\
\hline \hline
\end{tabular}

capital providers can make well informed decisions on optimal Tier 1-Tier 2 capital structuring.

\subsection{Life Insurance Annuity Firm Capital Structure Example}

We now move on to consider the capital structure results for the life insurance annuity firm example.

The first graph in Figure 3 shows 99.5th percentile economic capital for the range of Tier 2 capital backings of economic capital considered, with Pillar 1 minimum regulatory capital also shown for comparison. Again, as expected, economic capital increases as the amount of Tier 2 capital backing of economic capital increases, with Pillar 1 capital again being a poor proxy for economic capital, as has been noted previously by Porteous and Tapadar (2005).

In the second graph in Figure 3 we show the corresponding ROEC probability density function estimates, with associated summary statistics shown in Table 5. From this graph and table it can be seen that, as Tier 1 capital is

TABLE 5

Summary Statistics for 99.5Th Percentile ROEC for a Life Insurance Annuity Firm with Different Tier1-Tier2 Capital Structures $(\mu=$ Mean, $\sigma=$ Standard Deviation, $Q_{1}=$ First Quartile, $Q_{2}=$ Second Quartile (Median), $Q_{3}=$ Third Quartile).

\begin{tabular}{c|cccccc}
\hline \hline & $\mu$ & $\sigma$ & Sharpe Ratio & $Q_{1}$ & $Q_{2}$ & $Q_{3}$ \\
\hline Pillar 1 & 0.041 & 0.014 & 2.922 & 0.033 & 0.041 & 0.049 \\
$0 \%$ Tier 2 & 0.039 & 0.009 & 4.329 & 0.034 & 0.040 & 0.045 \\
$25 \%$ Tier 2 & 0.040 & 0.011 & 3.593 & 0.033 & 0.040 & 0.047 \\
$50 \%$ Tier 2 & 0.040 & 0.014 & 2.830 & 0.032 & 0.041 & 0.049 \\
$75 \%$ Tier 2 & 0.041 & 0.020 & 2.043 & 0.029 & 0.042 & 0.054 \\
$100 \%$ Tier 2 & 0.043 & 0.036 & 1.174 & 0.023 & 0.045 & 0.065 \\
\hline \hline
\end{tabular}



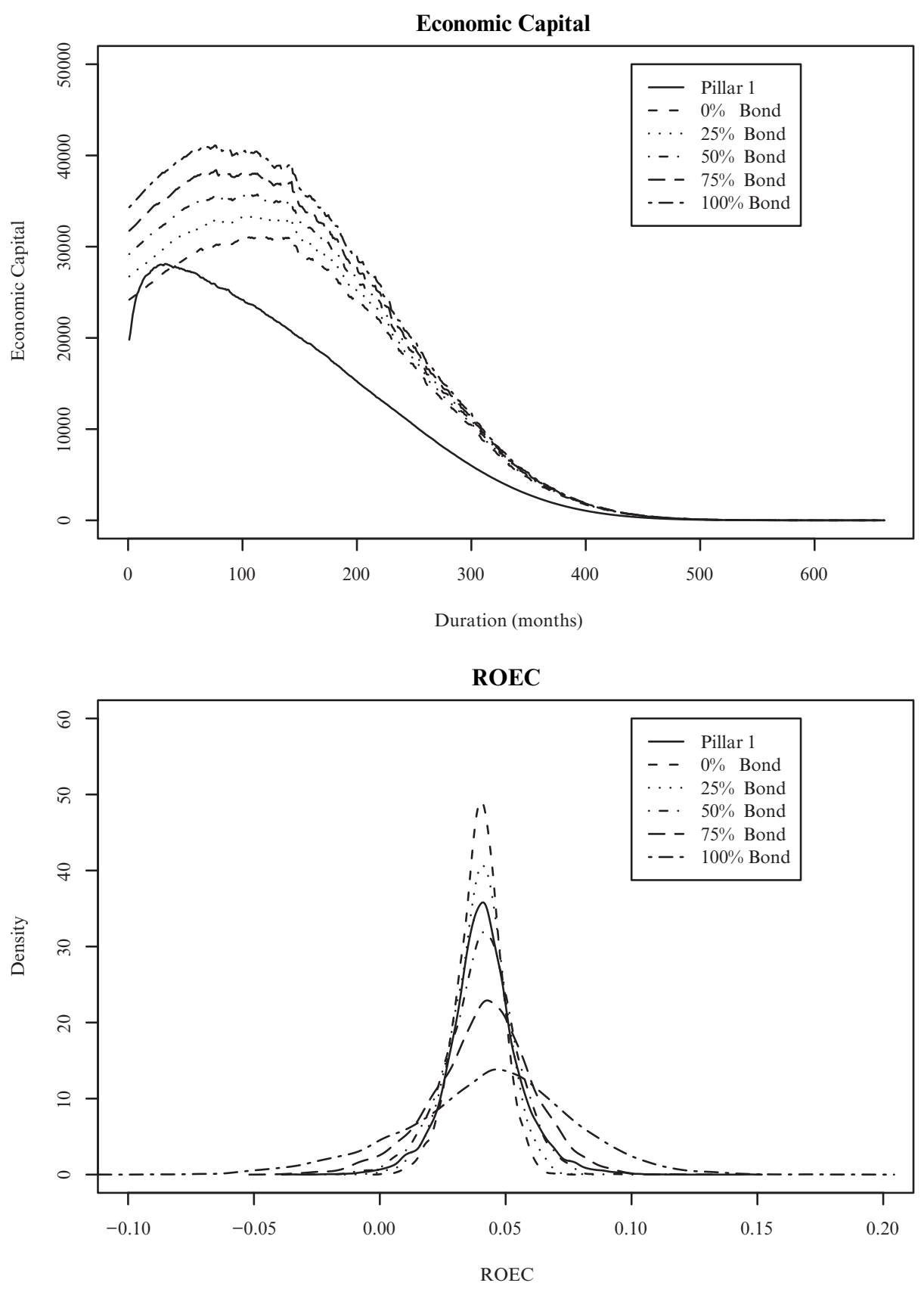

Figure 3: Annuity: 99.5th Percentile Economic Capital and ROEC Probability Density Functions for Different Tier1-Tier2 Capital Structures. 
geared up with Tier 2 capital, the location of the ROEC density functions remains essentially unaltered and symmetric. The densities become steadily more diverse, however, as Tier 1 capital is progressively geared up.

Unlike the banking example, therefore, the Tier 1 capital providers of this life insurance annuity firm have little to gain by gearing up their Tier 1 capital. In fact, all that they achieve by doing this is to increase the riskiness of their returns. Note that, because the ROEC densities have similar locations and are all symmetric in this example, a Sharpe ratio analysis gives the same conclusion.

\subsection{Capital Structure General Conclusions}

Based on the two examples presented in this Section, the broad conclusions that we can arrive at are as follows:

1. In the retail mortgage bank example, gearing up Tier 1 capital with Tier 2 capital is beneficial to the providers of the Tier 1 capital. This is because the ROEC probability density function shifts to the right, and become more positively skewed as gearing increases. Both of these effects mean that the Tier 1 capital providers are more likely to earn "high" returns when gearing is itself "high".

2. In the life insurance annuity firm example, on the contrary, gearing up Tier 1 capital with Tier 2 capital is not in the best interests of the Tier 1 capital providers. This is because the ROEC probability density function's location is broadly unaltered as gearing increases, but its spread becomes wider, whilst remaining broadly symmetric. In other words, the returns that the Tier 1 capital providers can expect to earn remain broadly unaltered, but the volatility of these returns increases, as gearing itself increases. So the Tier 1 capital providers have little to gain from gearing up their Tier 1 capital with Tier 2 capital.

3. In order to reach an informed decision on optimal Tier 1-Tier 2 capital structure, the Tier 1 capital providers must consider the full shape of the ROEC probability density functions, rather than just one summary statistic which has the potential to mislead.

In order to understand the different behaviour of these two examples we need to consider the different asset-liability structures of the retail mortgage bank and the life insurance annuity firm.

For the retail mortgage bank, both the asset and liability side of the mortgage book balance sheet have relatively "short" durations, with the asset side, the mortgages, being longer than the liability side, wholesale funding which reprices monthly. For the life insurance annuity firm example, both the asset and liability side of the insurance fund balance sheet have "long" durations, with the liability side longer initially and the asset side longer later on in the firm projection, as the annuitants age and the annuity liability shortens. 
It is this relative long duration of the life insurance annuity firm, as compared to the retail mortgage bank, that explains the different behaviour of the bank and life insurance examples. When Tier 2 capital is introduced to gear up Tier 1 capital, the consequent economic capital increase, over and above the base economic capital amount, is larger for long duration firms than for short duration firms.

In fact, the longer the outstanding duration of the firm projection, the more additional economic capital is required to protect the Tier 2 capital providers. This is because, the longer duration projections always contain at least the shorter duration projection extreme scenarios. As well as geared economic capital increases being larger absolutely for longer duration projections, our examples also indicate that the increases are larger relatively.

So, in the life insurance annuity firm example, when Tier 2 capital is introduced, economic capital increases by large amounts, relative to the retail mortgage bank example. This acts as a drag on the life insurance annuity firm ROEC probability density function and prevents it from shifting location to the right as gearing increases.

In other words, the geared economic capital increase nullifies the anticipated higher and more volatile returns earned on the geared Tier 1 capital. For the retail mortgage bank example, the corresponding economic capital increases are not large enough to achieve this and the higher geared Tier 1 capital returns dominate.

It is this difference in the asset-liability structures of the two firms that explains the differing results of the examples.

\section{The Impact of Actual Capital Asset Allocation ON ECONOMIC CAPITAL}

In this Section, using the examples described in Sub-sections 4.2 and 4.3, we now consider the impact that actual capital asset allocation has on a firm's economic capital amount and the corresponding risk adjusted returns earned on the firm's Tier 1 capital. Throughout the Section, we assume that economic capital is backed entirely by Tier 1 capital and that the actual capital backing Pillar 1 minimum regulatory capital is allocated to cash.

The four different types of UK assets that we assume the firm's actual capital is allocated to are as follows:

- Short term cash.

- Long term government bonds.

- Long term corporate bonds.

- Equities.

These asset categories are modelled stochastically, as described in Sub-section 4.1.1.

Allocating actual capital to more risky, but higher earning assets, relative to cash, causes firm profits to increase, on average, but to be more volatile. 
Economic capital therefore decreases if the higher profit effect dominates the higher volatility effect, and vice versa. These higher and more volatile profits are therefore spread across either higher, or lower, amounts of Tier 1 capital, depending on whether the associated economic capital amounts increase, or decrease. Given all of these moving parts, it is far from obvious, therefore, to see if allocating actual capital to more risky, but higher earning, assets increases the risk adjusted returns earned by the Tier 1 capital providers.

As with the Tier 1-Tier 2 capital structuring examples discussed above, our results are again presented in the form of figures and tables.

\subsection{Bank Actual Capital Asset Allocation Example}

The first graph shown in Figure 4 displays 99.5th percentile economic capital for the range of actual capital asset allocations considered. Pillar 1 minimum regulatory capital is also shown for comparison.

It can be seen that economic capital does not vary too much by actual capital asset allocation, with the economic capital curves being very tightly bunched together. Differences between the curves are, however, statistically significant. Generally speaking, assets with "high" expected returns will reduce economic capital, whereas assets with "high" volatility will tend to increase economic capital. The relative sizes of these expected returns and volatilities clearly also have an impact.

The graph shows that, at short durations, economic capital is lowest when actual capital is allocated to cash, mainly due to its low volatility, and greatest for government bond allocation, mainly due to its low expected returns, relative to its higher volatility.

The second graph in Figure 4 shows the corresponding ROEC probability density function estimates, including that for Pillar 1 capital, estimated from the simulations used to develop the example.

In Table 6, we show various ROEC summary statistics, based on the simulations used to construct the example, and once more, including the Sharpe ratio.

TABLE 6

Summary Statistics for 99.5Th Percentile ROEC for a Bank with Different Actual Capital Asset Allocations $\left(\mu=\right.$ Mean, $\sigma=$ Standard Deviation, $Q_{1}=$ First Quartile, $Q_{2}=$ SeCond Quartile (Median), $Q_{3}=$ Third QuARTILE).

\begin{tabular}{l|cccccc}
\hline \hline & $\mu$ & $\sigma$ & Sharpe Ratio & $Q_{1}$ & $Q_{2}$ & $Q_{3}$ \\
\hline Pillar 1 & 0.344 & 0.238 & 1.443 & 0.173 & 0.323 & 0.493 \\
Cash & 0.198 & 0.136 & 1.450 & 0.101 & 0.188 & 0.285 \\
Govt Bond & 0.197 & 0.134 & 1.473 & 0.102 & 0.187 & 0.282 \\
Corp Bond & 0.203 & 0.137 & 1.488 & 0.106 & 0.193 & 0.289 \\
Equity & 0.220 & 0.141 & 1.555 & 0.119 & 0.208 & 0.308 \\
\hline \hline
\end{tabular}



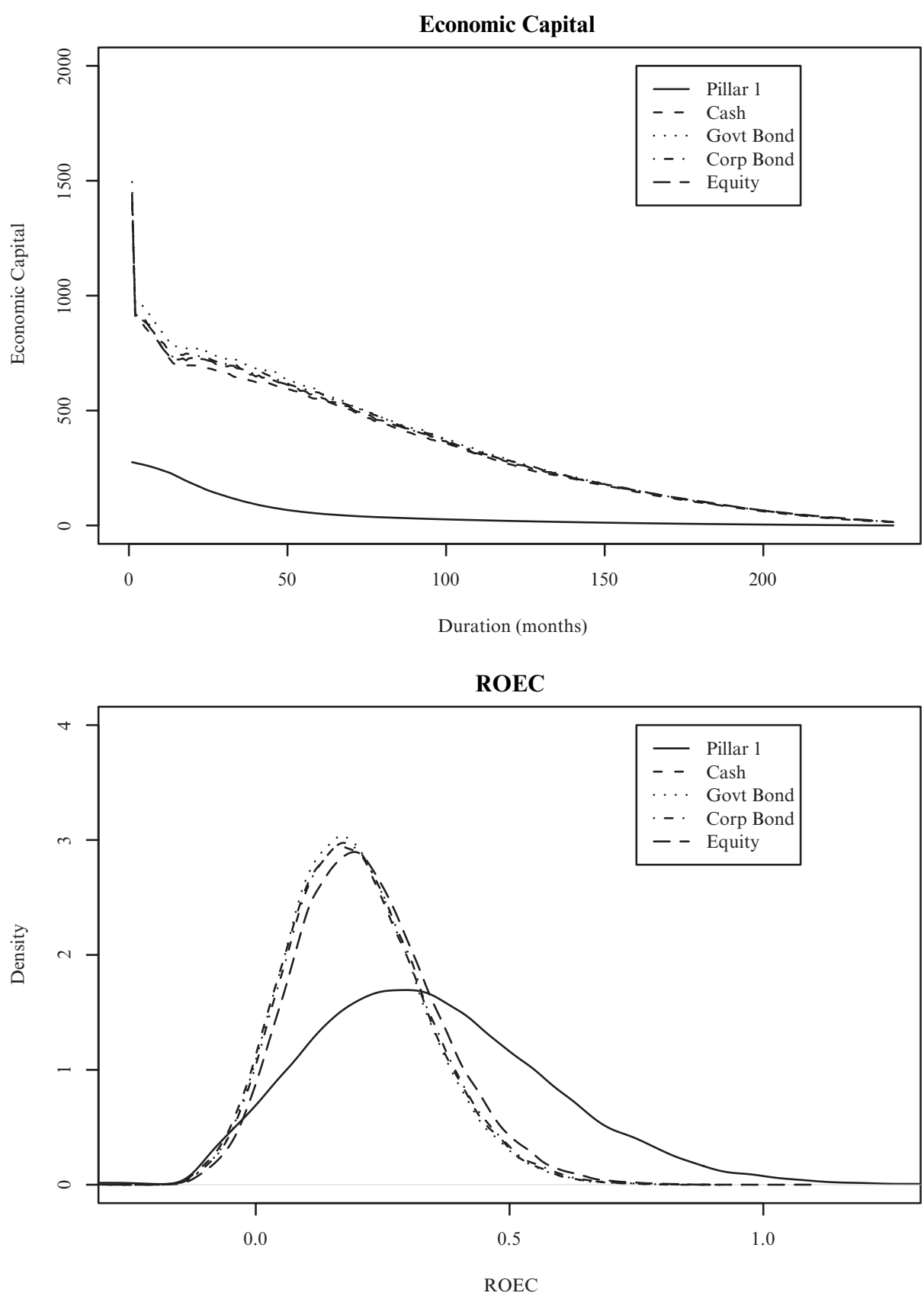

FIgure 4: Bank: 99.5th Percentile Economic Capital and ROEC Probability Density Functions when Actual Capital is Allocated to Different Asset Categories. 
Inspection of the probability density functions shown in Figure 4 shows that, apart from equity asset allocation, the density functions are all very similar and very slightly positively skewed. In other words, allocating actual capital to cash, government bonds or corporate bonds does not have too much of an impact on ROEC. This behaviour can also be seen in the summary statistics shown in Table 6.

The only density function that stands out slightly is the one where actual capital is allocated to equity assets. This density is located further to the right and is more positively skewed than the other density functions. In other words, equity asset allocation increases expected returns and also the potential of positive upside on those returns. This behaviour can again be seen in the summary statistics shown in Table 6.

We have evidence, therefore, to conclude that, for this example, allocating actual capital to equity assets is advantageous for the Tier 1 capital providers.

It is also interesting to note from Table 6 that the same conclusion is reached if the Sharpe ratio is used to assess performance. The Sharpe ratio is again more reliable in this instance because the ROEC probability density functions have similar locations and are all reasonably symmetric.

\subsection{Life Insurance Annuity Firm Actual Capital Asset Allocation Example}

We now move on to consider actual capital asset allocation results for the life insurance annuity example.

The first graph in Figure 5 shows 99.5th percentile economic capital for the range of actual capital asset allocations considered in this article, with Pillar 1 minimum regulatory capital also shown for comparison.

It can be seen that economic capital is lowest for cash asset allocation, followed by equity assets, then government bonds and finally corporate bonds. As described earlier, the ordering of these curves is driven, in the main, by the respective expected returns and volatilities of these asset categories.

It is interesting to note, however, that corporate bond asset allocation gives higher economic capital than government bonds. Given the construction of the example, this result is slightly counter intuitive as these two asset categories are modelled as having the same volatility, but with corporate bonds having higher expected returns. In fact, because the business assets of the annuity firm are invested in corporate bonds, there is a slight diversification benefit when allocating actual capital to government bonds, as compared to corporate bonds, and it is this effect that causes economic capital to fall. Diversification benefits between business and capital assets will be explored in more detail is a subsequent article.

In the second graph in Figure 5, we show the corresponding ROEC probability density function estimates, with associated summary statistics shown in Table 7. From this graph and table it can be seen that the distribution of the ROECs are reasonably symmetric and shift to the right as actual capital is 
Economic Capital
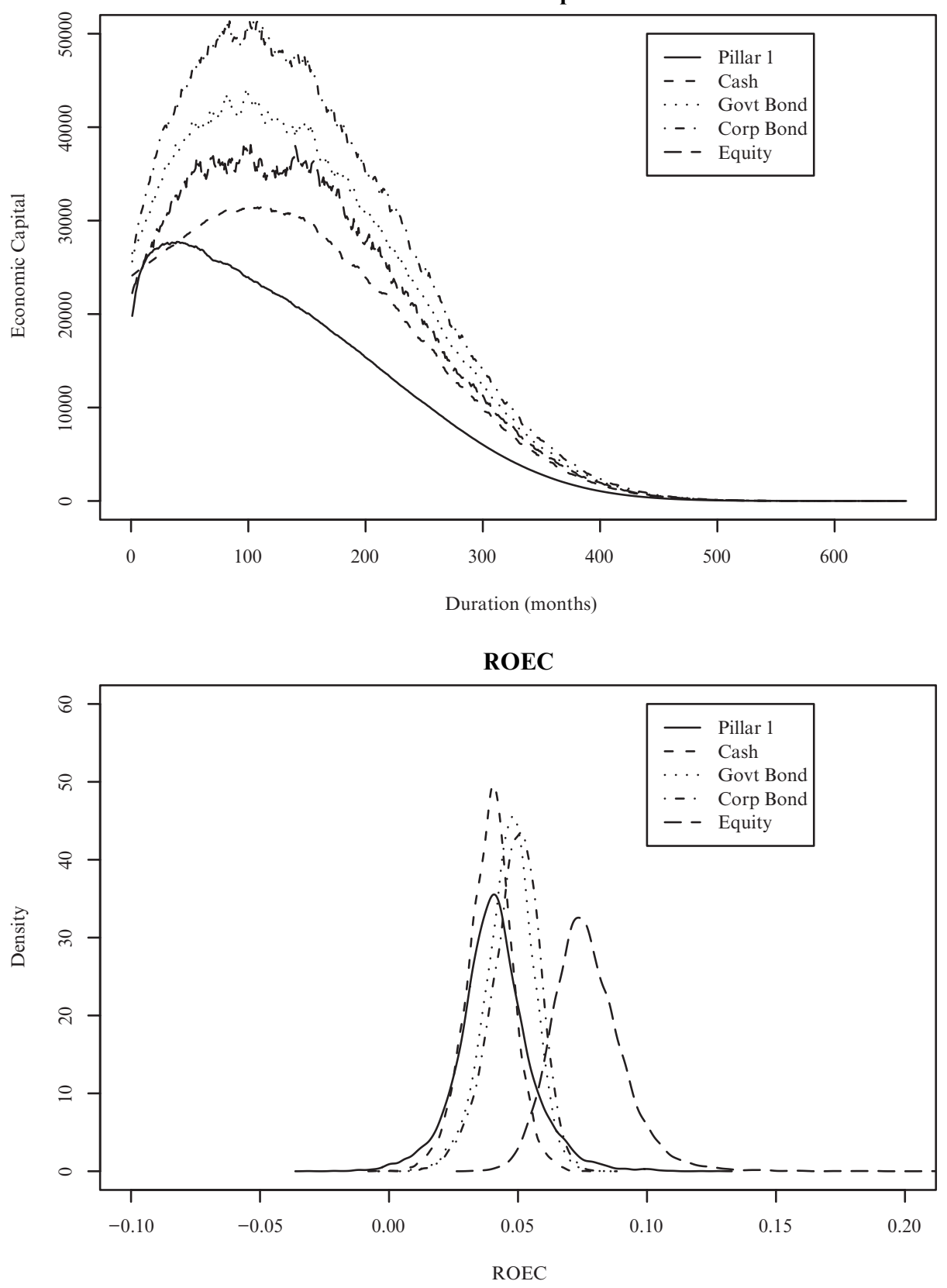

Figure 5: Annuity: 99.5th Percentile Economic Capital and ROEC Probability Density Functions when Actual Capital is Allocated to Different Asset Categories. 
TABLE 7

Summary Statistics for 99.5Th Percentile ROEC For a Life Insurance AnNuity Firm with Different Actual Capital Asset Allocations $(\mu=$ Mean, $\sigma=$ Standard Deviation, $Q_{1}=$ First Quartile, $Q_{2}=$ Second Quartile (Median), $Q_{3}=$ Third Quartile).

\begin{tabular}{l|cccccc}
\hline \hline & $\mu$ & $\sigma$ & Sharpe Ratio & $Q_{1}$ & $Q_{2}$ & $Q_{3}$ \\
\hline Pillar 1 & 0.041 & 0.014 & 2.886 & 0.033 & 0.041 & 0.049 \\
Cash & 0.039 & 0.009 & 4.288 & 0.033 & 0.039 & 0.045 \\
Govt Bond & 0.047 & 0.009 & 4.912 & 0.041 & 0.047 & 0.053 \\
Corp Bond & 0.049 & 0.010 & 5.021 & 0.043 & 0.049 & 0.055 \\
Equity & 0.077 & 0.020 & 3.814 & 0.068 & 0.076 & 0.085 \\
\hline \hline
\end{tabular}

progressively allocated to cash, then government bonds, corporate bonds and, finally, equity assets. Moreover, as with the banking example, the equity asset allocation shift is the largest.

Similar to the banking example, therefore, it can be seen that the Tier 1 capital providers have a real incentive for firms to allocate their actual capital to more risky assets than cash.

The Sharpe ratio analysis indicates that allocating actual capital to corporate bonds may be optimal for Tier 1 capital providers who assess risk using volatility, or standard deviation. This conclusion is probably broadly appropriate for these types of Tier 1 capital providers and the Sharpe ratio analysis works reasonably well in this example because the ROEC density functions are symmetric.

Nevertheless, the Sharpe ratio still misses the genuine upside potential of allocating actual capital to equity assets, which is apparent from the full ROEC probability density functions. For this reason, we feel that consideration of the full ROEC density functions, rather than one simple summary statistic, will always result in better asset allocation decisions.

\subsection{Actual Capital Asset Allocation General Conclusions}

Based on the two examples presented in this Section, the broad conclusions that we can arrive at are as follows:

1. The actual capital asset allocation decision does not have a material impact on the size of the retail mortage bank's economic capital requirements. As discussed earlier, the reason for this is the relative shortness of the mortgage book's balance sheet. As a consequence, the projections are too short for the actual capital asset allocation decision to fundamentally alter the extreme scenarios that drive the bank's economic capital amounts.

2. The actual capital asset allocation decision does have a material impact on the size of the life insurance annuity firm's economic capital requirements, with the corporate bond economic capital curve being particularly high. 
Again, the main reason for the difference between the bank and the life insurance annuity firm is that the insurance fund's balance sheet is much longer and this gives the actual capital assets sufficient time to influence the extreme scenarios that drive the life insurance annuity firm's economic capital requirements.

3. In terms of the Tier 1 capital providers ROECs, for both the retail mortgage bank and the life insurance annuity firm, the Tier 1 capital providers are better off if firms allocate their capital to riskier, but higher earning, assets. The higher returns on the more risky assets dominate the corresponding economic capital increases. This is clearly an important conclusion as many firms do, in fact, allocate capital to risky assets and our examples provide a rigorous rationale to justify this.

4. In order to reach an informed decision on optimal asset allocation, the Tier 1 capital providers need to consider the full shape of the ROEC probability density function, rather than just one summary statistic, which has the potential to mislead.

\section{The Joint Impact of Tier 1-Tier 2 Capital Structure and Actual Capital Asset Allocation on Economic CAPital}

We have also carried out work, on both the banking and life insurance annuity firm examples, where the Tier 1-Tier 2 capital structure of the firm is varied, whilst firm actual capital is allocated 100 per cent to equity assets.

Our results are again presented in the form of a series of figures and tables, as described below and we assume that the capital backing Pillar 1 minimum regulatory capital, is also allocated to equity assets.

\subsection{Bank Joint Capital Structure and Actual Capital Asset Allocation Example}

The first graph shown in Figure 6 displays 99.5th percentile economic capital for the range of Tier 2 capital backings considered. Pillar 1 minimum regulatory capital is also shown for comparison.

The second graph in Figure 6 shows corresponding probability density function estimates for earned rates of return on Tier 1 capital, as generated by the simulations used to develop this example and Table 8 gives corresponding ROEC summary statistics,

Comparing Figure 6 to Figure 2, and Table 8 to Table 4, shows that the geared economic capital curves are hardly altered by allocating actual capital to equity assets, rather than cash. Again, the shortness of the bank projection does not allow the more volatile equity assets sufficient time to materially affect the bank's projected extreme scenarios that drive economic capital.

It can also be seen that the equity asset capital allocation ROEC probability density functions are shifted to the right and are more positively skewed than 

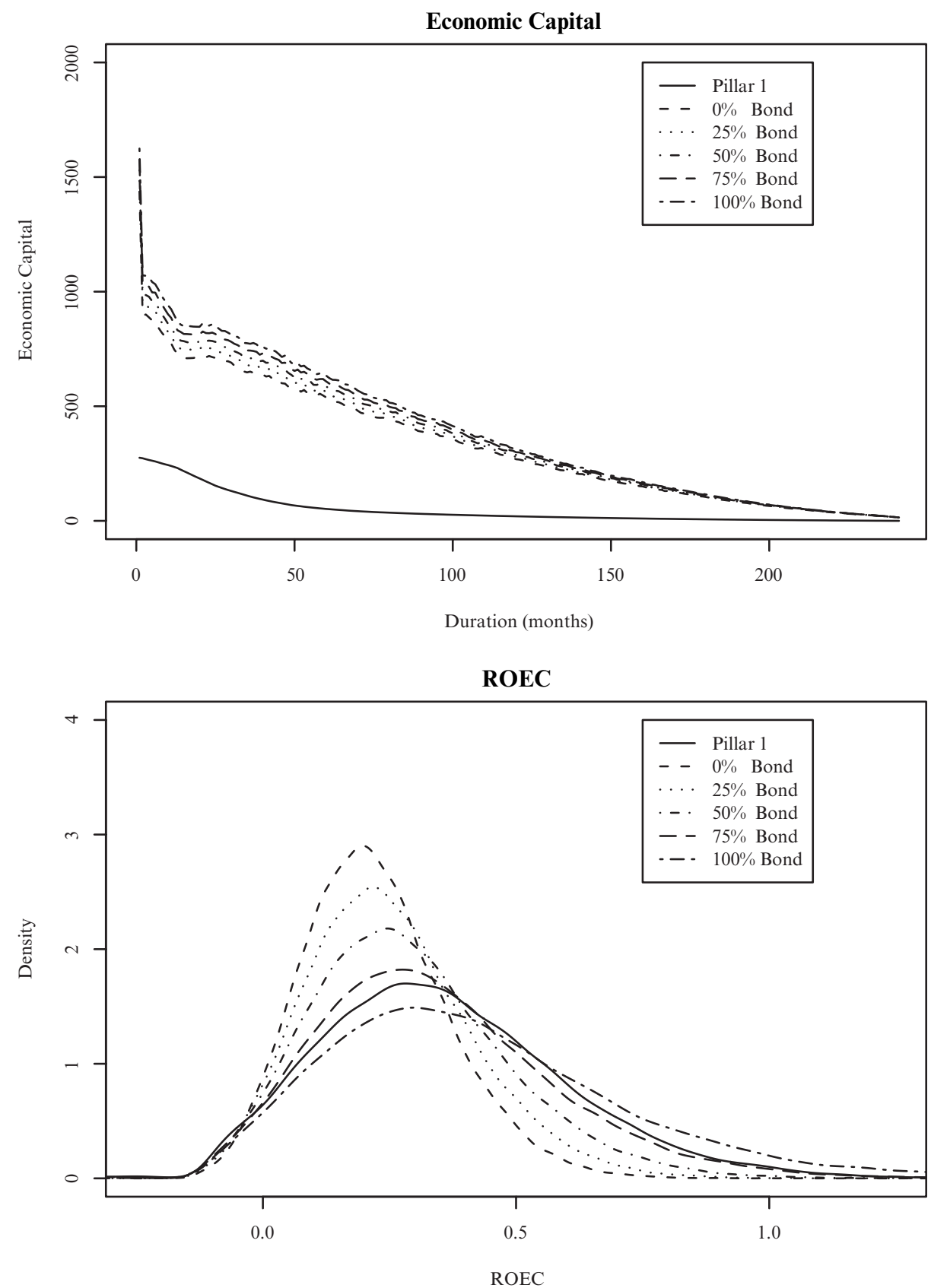

Figure 6: Bank: 99.5th Percentile Economic Capital and ROEC Probability Density Functions for Different Tier1-Tier2 Capital Structures when Actual Capital is Allocated to Equities. 
TABLE 8

Summary Statistics for 99.5Th Percentile ROEC for a Bank with Different Tier 1-Tier2 Capital Structures when Actual Capital is Allocated to Equity Assets ( $\mu=$ Mean, $\sigma=$ Standard Deviation, $Q_{1}=$ First Quartile, $Q_{2}=$ Second Quartile $\left(\right.$ Median), $Q_{3}=$ Third Quartile).

\begin{tabular}{c|cccccc}
\hline \hline & $\mu$ & $\sigma$ & Sharpe Ratio & $Q_{1}$ & $Q_{2}$ & $Q_{3}$ \\
\hline Pillar 1 & 0.355 & 0.244 & 1.452 & 0.181 & 0.333 & 0.504 \\
$0 \%$ Tier 2 & 0.222 & 0.143 & 1.549 & 0.121 & 0.211 & 0.310 \\
$25 \%$ Tier 2 & 0.250 & 0.166 & 1.511 & 0.133 & 0.236 & 0.350 \\
$50 \%$ Tier 2 & 0.287 & 0.195 & 1.471 & 0.149 & 0.268 & 0.404 \\
$75 \%$ Tier 2 & 0.339 & 0.236 & 1.438 & 0.172 & 0.312 & 0.477 \\
$100 \%$ Tier 2 & 0.417 & 0.300 & 1.393 & 0.205 & 0.376 & 0.582 \\
\hline \hline
\end{tabular}

their cash equivalents. This is due to the higher and more volatile returns that equity assets generate relative to cash.

So, we can conclude that, for each level of gearing considered, allocating actual capital to equity assets, rather than cash, is beneficial to the Tier 1 capital providers. It is also still the case that, when allocating actual capital to equity assets, gearing up Tier 1 capital with Tier 2 capital is beneficial to the Tier 1 capital providers.

The Sharpe ratio is again seen to be unhelpful.

\subsection{Life Insurance Annuity Firm Joint Capital Structure and Actual Capital Asset Allocation Example}

The first graph in Figure 7 shows 99.5th percentile economic capital for the range of Tier 2 capital backings of economic capital considered with Pillar 1 minimum regulatory capital also shown for comparison.

In the second graph in Figure 7 we show the corresponding ROEC probability density function estimates, with associated summary statistics shown in Table 9.

Comparing Figure 7 to Figure 3, and Table 9 to Table 5, shows that the economic capital curves are significantly higher when actual capital is allocated to equities, as compared to cash. Compared to the banking example above, it is the longer duration of the life insurance annuity firm that allows the more volatile equity assets to have an impact on the extreme scenarios that drive economic capital.

It can also be seen that, when allocating actual capital to equity assets, gearing causes the ROEC probability density functions to shift to the right and to become more positively skewed. In other words, capital gearing, in conjunction with allocating actual capital to equity assets, is advantageous to the Tier 1 capital providers as they are then more likely to earn higher returns on their capital. The Sharpe ratio again leads to the opposite conclusion, due to asymmetries in the density functions. 

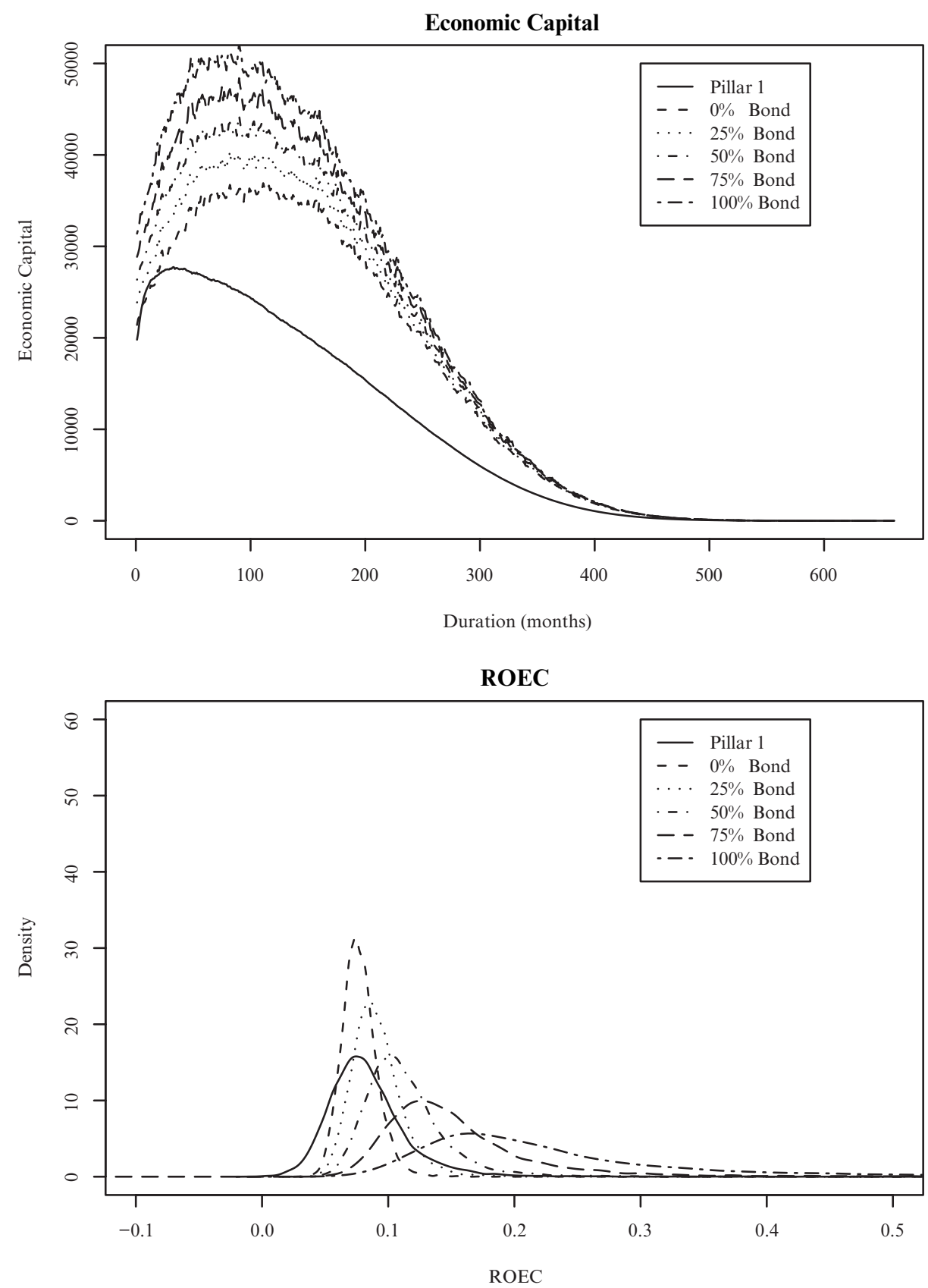

FIgURE 7: Annuity: 99.5th Percentile Economic Capital and ROEC Probability Density Functions for Different Tier1-Tier2 Capital Structures when Actual Capital is Allocated to Equity Assets. 
TABLE 9

Summary Statistics for 99.5Th Percentile ROEC for a Life Insurance AnNuity Firm with Different Tier 1-Tier2 Capital Structures when Actual Capital is Allocated to Equity Assets ( $\mu=$ Mean, $\sigma=$ Standard Deviation, $Q_{1}=$ First Quartile, $Q_{2}=$ Second Quartile (Median), $Q_{3}=$ THIRD QUARTILE).

\begin{tabular}{c|cccccc}
\hline \hline & $\mu$ & $\sigma$ & Sharpe Ratio & $Q_{1}$ & $Q_{2}$ & $Q_{3}$ \\
\hline Pillar 1 & 0.084 & 0.042 & 2.018 & 0.063 & 0.079 & 0.098 \\
$0 \%$ Tier 2 & 0.078 & 0.029 & 2.700 & 0.068 & 0.076 & 0.085 \\
$25 \%$ Tier 2 & 0.092 & 0.035 & 2.627 & 0.078 & 0.089 & 0.101 \\
$50 \%$ Tier 2 & 0.114 & 0.049 & 2.322 & 0.092 & 0.108 & 0.128 \\
$75 \%$ Tier 2 & 0.160 & 0.111 & 1.436 & 0.116 & 0.141 & 0.176 \\
$100 \%$ Tier 2 & 0.300 & 0.567 & 0.530 & 0.157 & 0.203 & 0.282 \\
\hline \hline
\end{tabular}

This is contrary to the results shown in Section 5 where capital gearing, in conjunction with allocating actual capital to cash, was seen to be against the interests of the Tier 1 capital providers. There is, therefore, a strong interaction effect between capital structure and actual capital asset allocation for the life insurance firm example, which is explained as follows.

As has been described previously, the relatively long duration of the life insurance annuity firm causes economic capital to increase materially with gearing. When actual capital is allocated to cash, this effect nullifies the higher and more volatile geared Tier 1 capital returns that might be anticipated. However, when actual capital is allocated to equity assets, the higher returns that are earned on the equity assets are more than sufficient to dominate the consequent economic capital increases that arise, both from gearing, and from allocating actual capital to equity assets.

In this sense, gearing up capital is only beneficial if it is carried out in conjunction with an actual capital higher risk asset allocation strategy. It is interesting to note that, in practice, many firms may not be prepared to go as far as this.

Finally in this Section, for completeness, we can also see that, for each level of gearing assumed, allocating actual capital to equity assets is beneficial for the Tier 1 capital providers.

\subsection{Joint Capital Structure and Actual Capital Asset Allocation General Con- clusions}

Based on the two examples presented in this Section, the broad conclusions that we can arrive at are as follows:

1. For the retail mortgage bank, capital gearing is even more beneficial to the Tier 1 capital providers when actual capital is allocated to equity assets, 
than when it is allocated to cash. For each level of gearing assumed, allocating actual capital to equity assets, rather than to cash, is beneficial.

2. For the life insurance annuity firm, gearing becomes beneficial, rather than detrimental, to the Tier 1 capital providers when actual capital is allocated to equity assets, rather than to cash. For each level of gearing assumed, allocating actual capital to equity assets, rather than to cash, is beneficial.

3. The different behaviour of the retail mortgage bank and the life insurance annuity firm is explained by the different asset-liability structures of their balance sheets and, in particular, their differing lengths.

\section{Conclusions}

Important current trends in financial services markets affecting the structure, asset allocation and management of capital for financial services firms are as follows:

1. Financial services markets are globalising and are becoming ever more competitive and commoditised.

2. Capital providers are becoming more sophisticated in their assessment of risk and in their ability to quantify risk adjusted performance.

3. Regulatory and economic capital requirements are converging.

As these trends strengthen, and gather pace, it is essential that financial services firms and conglomerates manage their capital as efficiently as possible in order to stay competitive. For otherwise, firms will risk delivering inferior risk adjusted returns to their equity capital providers, so resulting in poor share price performance. This, in turn, will make the raising of fresh capital, to further support and develop their businesses, more difficult.

Perhaps most importantly, however, ineffective capital management is bad not just for the financial services industry itself, but also for the wider economy more generally. If capital providers are not earning full and fair risk adjusted returns, this can result in capital market inefficiencies, distortions and misallocations.

In this article, for specific financial services firm examples, we have shown how firm economic capital and risk adjusted performance depend on both Tier 1-Tier 2 capital structure and actual capital asset allocation. For the examples considered here, we have found that:

- Gearing up Tier 1 capital with Tier 2 capital, and allocating actual capital to high earning risky assets, generally increases economic capital, with the increases being higher for the life insurance annuity firm. The asset-liability structures of the two firms and, in particular, their relative lengths explains this difference. Generally speaking, longer duration balance sheets are more sensitive to gearing and to allocating actual capital to risky assets.

- For the retail mortgage bank, gearing up Tier 1 capital with Tier 2 capital, and allocating actual capital to higher earning but more risky assets, which 
both increase economic capital, are individually, and jointly, beneficial to Tier 1 capital providers. Most benefit is achieved when capital is both highly geared and allocated to risky assets.

- For the life insurance annuity firm, gearing up Tier 1 capital with Tier 2 capital is beneficial to the Tier 1 capital providers only when actual capital is allocated to risky, but higher earning assets. When actual capital is allocated to lower earning, but safer assets, gearing is detrimental to the Tier 1 capital providers. Again, most benefit is achieved when capital is both highly geared and allocated to risky assets. The asset-liability structures of the two firms considered and, in particular, their respective lengths again explain the bank-insurer differences.

- In order to reach an informed decision on the optimal Tier 1-Tier 2 capital structure and actual capital asset allocation, the Tier 1 capital providers need to consider the full shape of the ROEC probability density functions, rather than just one summary statistic, which has the potential to mislead.

In practice, we recommend that each firm must analyse its own businesses, and circumstances, before it can draw any clear conclusions on the optimality, or otherwise, of its own capital structuring, asset allocation and management processes. Key to this analysis will be the development and implementation of robust and accurate risk management tools that allow firms to self assess and quantify the risks that they are running across all of their businesses.

\section{REFERENCES}

Dev, A. (2004) Economic Capital: A Practitioner Guide. Risk Books, London.

Lauritzen, S. (1996) Graphical Models. Clarenden Press, Oxford.

Matten, C. (2000) Managing Bank Capital - Capital Allocation and Performance Measurement. Wiley.

Modigliani, F. and Miller, M. (1958) The Cost of Capital, Corporation Finance and the Theory of Investment. The American Economic Review 48, 261-297.

Porteous, B.T., McCulloch, L. and Tapadar, P. (2003) An Approach to Economic Capital for Financial Services Firms. Risk Magazine, April, 28-31.

Porteous, B.T. (2004) Economic Capital for Life Insurance With Profits Long Term Business Funds. Journal of Risk 6, 1-6.

Porteous, B.T. (2005) The "Benefits" of Smoothing. Life and Pensions Magazine, August/September, $42-48$.

Porteous, B.T. and TAPADAR, P. (2005) Economic Capital and Financial Risk Management for Financial Services Firms and Conglomerates. Palgrave MacMillan.

Rajan, R.G. and Zingales, L. (1995) What Do We Know About Capital Structure? Some Evidence from International Data. Journal of Finance 50, 1421-1460.

Willets, R.C., Gallop, A.P., Leandro, P.A., Lu, J.L.C., MacDonald, A.S., Miller, K.A., Richards, S.J., Robjohns, N., Ryan, J.P. and Waters, H.R. (2004) Longevity in the 21st Century. British Actuarial Journal 10, 685-832.

Willets, R.C. (2004) The Cohort Effect: Insights and Explanations. British Actuarial Journal 10, 833-877. 


\section{APPENDIX 1}

BANK EXAMPLE

\section{Economic assumptions}

Risk discount rate used in economic capital calculation

Corporate tax rate
The return earned on the assets that firm actual capital is allocated to, as generated by the stochastic model, parameterised according to Table 1. $30 \%$.

\section{Mortgage product economic capital assumptions}

Average loan size
Loan to value percentage
Average term
Interest only/capital rep
ment mix
Standard variable rate
1 year discount
Redemption penalty

Flexible features

Cost of funding

Expected credit risk losses
$£ 100,000$.

$100 \%$.

20 years.

Only a capital repayment mortgage is used in the examples.

As generated by the stochastic model.

$1.0 \%$ deduction from standard variable rate.

$2.5 \%$ of the loan outstanding at that duration within the first 12 months. No penalty is levied beyond the first 12 months.

No.

The short term UK cash yield as generated by the stochastic model plus $0.1 \%$.

Loss given repossession ("LGR") is calculated as:

$\mathrm{LGR}=($ loan outstanding $)-($ property value $) \times 0.95$, if positive, and zero otherwise.

Selling costs and late interest are assumed to amount to $5 \%$ of the value of the property on repossession.

The property value is estimated as its starting value increased in line with UK HPI, as generated by the stochastic model.

Expected and high probabilities of repossession ("PR") are assumed as follows:

Expected PR $=0.0025$ p.a.

High PR $=0.005$ p.a.

High PRs are used if the standard variable rate, as generated by the stochastic model, exceeds its unconditional expected value plus twice its unconditional standard deviation, as shown in Table 1, or if LGR > $1 \%$ of the property value at that duration.

In other words, High PRs are used if either mortgage rates are high, or if a loss of at least $1 \%$ of the property value would be made on repossessing and selling the property. 
Fixed expenses

Fixed expense inflation Variable initial expense

Annual prepayment rates

Basel 2 Pillar 1 minimum regulatory capital requirement
For defaults, it is assumed that 1 in 5 defaults lead to a repossession and loss given defaults are, on average, 1/5th of loss given repossessions. These default probabilities and losses are then used to compute the Basel 2 Pillar 1 credit risk capital requirement.

$£ 300$ (acquisition), £50 p.a. (maintenance), £100 (closure).

UK RPI as generated by the stochastic model. $0.5 \%$ of initial loan.

Two prepayment rate series are used:

Expected: $1 \%, 25 \%, 15 \%, 12.5 \%$ and $10 \%$ p.a. of the loan outstanding at durations $1,2,3,4$, and $\geq 5$ years High: $1 \%, 50 \%, 20 \%, 15 \%$ and $10 \%$ p.a. of the loan outstanding at durations $1,2,3,4$, and $\geq 5$ years.

Expected lapse rates are used unless the standard variable rate, as generated by the stochastic model, is larger than its unconditional expected value plus twice its unconditional standard deviation as shown in Table 1. In other words, high standard variable rates are a cause of high prepayment rates.

Advanced internal ratings based approach for the retail credit risk capital requirement, where the probabilities of default and loss given defaults, as described above, are used. The operational risk capital requirement is calculated using the standardised approach and is based on the net interest income earned on the loan at each duration, gross of expenses. 


\section{APPENDIX 2 \\ Life InSURAnCE ANNUITy ExAmple}

\section{Economic assumptions}

Risk discount rate used in economic capital calculation

Asset allocation of non profit long term business fund ("NPLTBF")

Long term UK corporate bond gross yield

Long term UK government bond yield

Term of long term UK corporate bond assets backing the annuity Corporate tax rate
The return earned on the assets that firm actual capital is allocated to, as generated by the stochastic model, parameterised according to Table 1. $100 \%$ in long term UK corporate bonds.

The long term UK corporate bond yield, as generated by the stochastic model, parameterised according to Table 1.

The long term UK government bond yield, as generated by the stochastic model, parameterised according to Table 1 .

15 years. At the end of each month, assets are sold and reinvested in corporate bonds of duration 15 years, at the yield prevailing at the end of the month. $30 \%$.

\section{Annuity product economic capital assumptions}

Average single premium size Annuity income Mix of business

Mortality
$£ 250,000$.

Level $£ 1,500$ per month.

Joint life last survivor annuity for a male aged 65 and female aged 65.

Base mortality tables: PMA92Base, PFA92Base projected forward to 2005 using the published mortality improvement factors for these tables. See Continuous Mortality Investigation Bureau Report 17, Part 6 (www.actuaries.org.uk).

Stochastic mortality improvement factors. Improvement factors are assumed to be Normally distributed with the following expectations and standard deviations.

Male "cohort" expected improvement factors $(\mu)$ : $5 \%$ p.a. in year 1 of the projection, increasing by $0.25 \%$ p.a. for each subsequent year in the projection, up to an upper limit of $7.5 \%$ p.a. This upper limit is assumed to apply thereafter once it is reached.

Male improvement factor standard deviation $(\sigma): 0.5 \%$. Female "cohort" expected improvement factors $(\mu)$ : $4.25 \%$ p.a. in year 1 of the projection, increasing by $0.25 \%$ p.a. for each subsequent year in the projection, up to an upper limit of $7.5 \%$ p.a. This upper limit is assumed to apply thereafter once it is reached. 
Long term UK corporate bond modelled credit risk

Variable initial expense

Fixed expenses

Fixed expense inflation

Realistic and mathematical reserving method

Realistic reserving assumptions
Female improvement factor standard deviation $(\sigma)$ : $0.5 \%$.

The credit risk losses that we have assumed are as follows:

Expected corporate bond yield scenario: An annual probability of default equal to $0.5 \%$ and a loss given default of $25 \%$, giving a conditional expected credit risk loss of $0.125 \%$ p.a.

High corporate bond yield scenario: An annual probability of default equal to $2.5 \%$ p.a. and a loss given default of $75 \%$, giving a conditional expected credit risk loss of $1.8750 \%$ p.a.

High corporate bond scenarios are assumed to occur when the corporate bond yield exceeds its unconditional 90th percentile, according to the parameterisation set out in Table 1. In other words, high corporate bond yield scenarios happen with probability $10 \%$.

This gives an overall unconditional expected credit risk loss of $0.30 \%$ p.a.

As the unconditional expected yield differential between long term UK corporate bonds and long term UK government bonds, according to the parameterisation set out in Table 1, is $0.50 \%$ p.a., we have assumed that $0.30 \%$ p.a. is due to corporate bond expected credit risk losses, and the remaining $0.20 \%$ p.a. is due to the inferior liquidity of the corporate bonds.

$1 \%$ of the single premium.

$£ 500$ (acquisition), £25 p.a. (maintenance).

UK RPI as generated by the stochastic model.

Realistic/gross premium.

The realistic reserve at each time point is calculated as follows:

Annuity cashflows are projected using the values generated by the stochastic model. At each time point, the values generated by the stochastic model, and annuity cashflows, are projected forward deterministically using the expected values assumed in the stochastic model. The risk discount rate used for each time point going forward is the long term UK corporate bond yield as generated by the stochastic model at that time point, less $0.30 \%$ to cover unconditional credit risk losses.

If the NPLTBF is backed by long term UK government bonds, the risk discount rate used from each time point forward is the long term UK government bond yield, as generated by the stochastic model at that time point. 
Mathematical reserving assumptions
The mathematical reserve at each time point is calculated as for realistic reserves except that the risk discount rate used from that time point going forward is the long term UK government bond yield, as generated by the stochastic model at that time point.

Long term insurance capital $4 \%$ of mathematical reserves.

requirement ("LTICR")

Resilience capital requirement If the NPLTBF is backed by either long term UK corporate bonds, or long term UK government bonds, the additional asset-liability mismatch reserve needed to cover a $1.5 \%$ parallel shift in the yield curve, upwards or downwards, whichever requires the larger reserve.

Pillar 1 minimum regulatory capital requirement
The Pillar 1 regulatory capital requirement is calculated as:

1. The long term insurance capital requirement.

2. The resilience capital requirement.

3. The mathematical reserve less the realistic reserve at each time point, provided this difference is positive, or zero otherwise. This difference represents the margin for prudence implicit in the mathematical reserves.

\section{Bruce T. Porteous}

Head of UK Risk Capital Development,

Standard Life UK Financial Services,

30 Lothian Road,

Edinburgh, EH1 2DH.

Telephone: 0044-1312459307.

E-Mail (work): bruce_porteous@standardlife.com

E-Mail (personal): brucetporteous@gmail.com

\section{PRADIP TAPADAR}

Lecturer in Actuarial Science,

Institute of Mathematics, Statistics and Actuarial Science,

Cornwallis Building,

University of Kent,

Canterbury, CT2 7NF.

Telephone: 0044-1227824169.

E-Mail (work):P.Tapadar@kent.ac.uk

E-Mail (personal): ptapadar@gmail.com 